
cellular life/death balance in corals in

SUBJECT AREAS: GENE EXPRESSION

ENVIRONMENT

ZOOLOGY

PHYSIOLOGY

Received

14 September 2011

Accepted

20 October 2011

Published

17 November 2011

Correspondence and requests for materials should be addressed to T.A. (Tracy.ainsworth@ jcu.edu.au)

\section{response to stress}

\author{
Ainsworth T. D. ', Wasmund K. ${ }^{1}$, Ukani L. ${ }^{1,2}$, Seneca F. ${ }^{1,2}$, Yellowlees D. ${ }^{1}$, Miller D. ${ }^{1,2}$ \& Leggat W. ${ }^{1,2}$
}

${ }^{1}$ ARC Centre of Excellence for Coral Reef Studies, James Cook University Townsville, Australia, ${ }^{2}$ School of Pharmacy and Molecular Sciences, Faculty of Health and Molecular Sciences, James Cook University, Townsville, Australia.

Apoptotic cell death has been implicated in coral bleaching but the molecules involved and the mechanisms by which apoptosis is regulated are only now being identified. In contrast the mechanisms underlying apoptosis in higher animals are relatively well understood. To better understand the response of corals to thermal stress, the expression of coral homologs of six key regulators of apoptosis was studied in Acropora aspera under conditions simulating those of a mass bleaching event. Significant changes in expression were detected between the daily minimum and maximum temperatures. Maximum daily temperatures from as low as $3^{\circ} \mathrm{C}$ below the bleaching threshold resulted in significant changes in both pro- and anti-apoptotic gene expression. The results suggest that the control of apoptosis is highly complex in this eukaryoteeukaryote endosymbiosis and that apoptotic cell death cascades potentially play key roles tipping the cellular life/death balance during environmental stress prior to the onset of coral bleaching.

C oral bleaching, or the loss of the endosymbiotic dinoflagellates from the tightly-coupled coral symbiosis, is an ecologically devastating global phenomenon occurring on coral reefs in response to environmental stress $^{1,2}$. The most widely occurring mass bleaching events have resulted from increased sea surface temperatures coupled with high light regimes, which result in stress events that exceed the physiological limit of the symbiotic organism ${ }^{2,3}$. Previous studies of the bleaching phenomenon point to a range of possible causes and complex molecular networks which drive the disassociation of the symbiosis (for reviews see ${ }^{4-6}$ ) but to date we do not understand the mechanisms that govern cellular changes or the initiation of stress responses in this complex eukaryote-eukaryote photosynthetic symbiosis ${ }^{7}$. Apoptotic cell death however has been proposed as one of several cellular mechanisms driving the breakdown of the symbiosis during thermal sea surface anomalies and coral bleaching events ${ }^{7-9}$. Understanding the complexity of coral responses to changing environmental conditions is a significant advance in coral biology and in determining the mechanisms which govern whole organism responses to environmental change ${ }^{10}$.

The apoptotic network conveys the interpretation, initiation and regulation of death signals within the cell, whereby an intricate network of proteins function to maintain the balance between life and death within a single cell $^{11-15}$. Both biotic and abiotic stimuli including exposure to ultraviolet light, starvation, heat stress, and viral and bacterial pathogens, trigger the regulation of the cell death pathway ${ }^{12,13,16}$. Specifically the $\mathrm{Bcl}-2$ family members within the cell death cascade are described as the sensors and regulators of the multitude of stress signals to the cell. The proteins within this family interact to govern the release of cytochrome $\mathrm{C}$ and permeabilization of the outer mitochondrial membrane and the organelle membranes during the onset of cell death ${ }^{17}$. It has recently been hypothesized that the type of the cell death signal or stimuli that is interpreted by the cell results in the initiation of a distinct molecular pathways within the cell death network that lead to apoptosis and that these signals may be specific to cell type ${ }^{18}$. The control of cell death execution is further regulated within the cell through the actions of various inhibitors, including members of the Bcl-2 and BIR families. Proteins act to prevent cell death in the cell through, for example, interactions of anti-apoptotic with pro-apoptotic Bcl-2 family members ${ }^{19-21}$ and the deactivation of cell death effectors such as caspases ${ }^{22}$. The role of cell death regulation and the associated molecules however is highly complex. For example the apoptosis inhibitor BIR which was initially characterised as a suppressor of apoptosis that blocks caspase-9 activity is now also recognised to have a broad range of functions, including the regulation of mitosis and cellular adaptation to stress ${ }^{23}$. Since first being described cell death regulation has been well documented to be significant in homeostasis, development and diseases of higher organisms (for reviews see $\mathrm{e}^{14,20,24,25}$ ). 
Apoptosis has however also been documented in many lower animals and the apoptotic networks of cnidarians appear to rival those of mammals in terms of complexity ${ }^{7,15,26}$. Members of the coral apoptotic repertoire (both pro- and anti-apoptotic proteins) have been documented in Hydra ${ }^{27-29}$, Nematostella ${ }^{15}$, and corals ${ }^{7,26}$, and include Bak-, Bax- and Bcl-2-like members of the Bcl-2 protein family ${ }^{30}$. There have been few functional studies on these molecules, but those that have been carried out are consistent with functional, as well as sequence conservation, with cnidarian and mammalian proteins having the same domain structure. Lasi et al. ${ }^{27}$ demonstrated strong apoptotic effects of two Hydra Bak-like proteins in cultured mammalian cells, whereas six other Bcl-2-related molecules inhibited camptothecin-induced apoptosis in the same system ${ }^{25}$. The predicted apoptotic gene repertoire of the coral Acropora digitifera based on the whole genome sequence implies the presence of approximately $10 \mathrm{Bcl}-2$ family members, six IAPs, as well as a large suite of caspases ${ }^{31}$. In the coral, Acropora millepora, a Bcl-2 homolog is heavily expressed in the aboral ectoderm during metamorphosis, presumably fulfilling an anti-apoptotic role ${ }^{32}$. In adult A. millepora, modest shifts in the relative expression of some pro- and anti-apoptotic Bcl-2 family members have been documented in response to thermal stress $^{33}$. Previous studies have also demonstrated Cnidarian apoptosis occurs during symbiont loss in response to thermal stress ${ }^{34,35}$. Gates ${ }^{8}$ first speculated on apoptosis as a key mechanism in thermal induced coral mortality and subsequently substantial evidence for apoptotic cell death occurring during symbiont loss has been presented ${ }^{33,34}$. There is however also morphological evidence for apoptotic cell death occurring within the coral gastrodermal tissue layer (which hosts the endosymbiotic dinoflagellate) from $3^{\circ} \mathrm{C}$ below the bleaching thresh$\mathrm{old}^{7}$, which is then subsequently only evident in both tissue layers (epithelial and gastrodermal) during exposure of the coral to bleaching temperatures and the breakdown of the symbiosis. The specific role of the complex array of coral apoptosis related genes in controlling cell death during environmental stress, in response to rapidly changing abiotic stimuli, and ultimately their role in coral mortality in response to climate change has not been widely investigated.

In referring to mammalian systems, Dial and Krosmeyer ${ }^{36}$ state that cell death operates to maintain homeostatsis and this is especially critical in long-lived animals that must integrate multiple physiological and pathological cell death signals. The coral holobiont is a long-lived colonial organism that is exposed to a myriad of complex and dynamic environmental and physiological conditions ${ }^{37}$. Understanding the control of cell death mechanisms in corals, and particularly their role in stress responses, will provide a greater insight into the biology of these organisms and their capacity to respond and adapt to environmental change. This study investigates the response of the molecular mechanisms governing primary cell death during abiotic stress (temperature and light) of the coral symbiosis. We selected a suite of regulatory molecules, including four Bcl-2 related proteins and members of the Inhibitors of Apoptosis (IAP) and Bax-Inhibitor-1 (BI-1) families in Acropora, and studied the expression of these in a laboratory experiment that simulates conditions occurring during the lead in to a coral bleaching event. The results of this study have implications for determining the mechanisms underlying coral bleaching and the recovery of coral colonies following bleaching events.

\section{Results}

Identification of target genes in A. aspera. Coral Bcl-2 family members, Bcl-2 and Bax have previously been characterised ${ }^{7}$, and the current study identifies two additional Bcl-2 family members, Bok and Bak from the coral $A$. aspera based on sequence homology within conserved $\mathrm{BH}$ domains (Table 2). The Acropora Bok has similarity to the previously described Bcl-2-like Ovarian killer (Bok), having conserved sequence identity within the characteristic pro-apoptotic $\mathrm{BH} 3$ region-binding site, a nuclear

\begin{tabular}{|lcc|} 
Table 1 & Primer sequences for use in quantitative PCR. \\
Gene & $\begin{array}{c}\text { Primer } \\
\text { direction }\end{array}$ & Primer sequence \\
\hline Bok like & $\mathrm{F}$ & GGATTGTGGCCTTGTACGCATTTG \\
Bok like & $\mathrm{R}$ & CCAACCGGATACATCACGAATAAACCT \\
Bak like & $\mathrm{F}$ & GTCCGGACGCACTTGAAGAACTT \\
Bak like & $\mathrm{R}$ & AGCATCAATTCATCGCCTATCTCT \\
Bax like & $\mathrm{F}$ & TCTACGAAACTGGCGACTCTTATG \\
Bax like & $\mathrm{R}$ & TAGGATGCGCTGTATTGGTGTTAT \\
Bcl-2 like & $\mathrm{F}$ & GTGGCGGACGAACTCATAGAAG \\
Bcl-2 like & $\mathrm{R}$ & TGTGGCATAAGTAGAAGCGTGTG \\
Bl-1 like & $\mathrm{F}$ & TGTTGTTGTGGCTTGTGCTGTA \\
BI-1 like & $\mathrm{R}$ & AAATCAACGGAATGCCAGACAAAGT \\
BIR like & $\mathrm{F}$ & GAGGCAGGCTTCTATCATTCTTC \\
BIR like & $\mathrm{R}$ & GGTTCCCATCCTTCAAGTCTTT \\
\hline
\end{tabular}

transporter domain, and the $\mathrm{BH} 2$ and $\mathrm{BH} 1$ conserved domains. The identified Acropora Bak-like protein has conservation within the $\mathrm{BH} 3, \mathrm{BH} 2$ and $\mathrm{BH} 1$ domain regions and the best match identified within NCBI is to the 188 amino acid Nematostella predicted Bak-like protein ${ }^{38}$, the sequence also contains one identified transmembrane domain. Similarly, we identify 2 key inhibitors of apoptosis, Bax inhibitor 1 (BI-1) and Survivin (Table 2) based on the presence of evolutionarily conserved domains. The identified Acropora BI-1-like protein is a 238 amino acid protein containing a highly conserved BI-1-like domain of 206 amino acids and 6 predicted transmembrane domains. The protein shows highest homology to a putative Nematostella BI-1-like protein of 238 amino acids ${ }^{38}$, although there is significant conservation within this domain across the phyla. Finally, a highly conserved protein with similarity to the BIR containing Survivin was identified based on conservation within the single 75 amino acid BIR domain which contains the characteristic zinc binding sites at amino acid position Cys58, Cys61, Cys85 and His78.

Thermal stress and the onset of bleaching in Acorpora aspera. Over the course of 8 days, $A$. aspera nubbins were subjected to increasing temperatures, culminating in exposure to $34^{\circ} \mathrm{C}$ upon which bleaching (loss of dinoflagellate symbionts or pigments) occurred (Figure 1b). The dark-adapted yields (Fv/Fm) (a standard method to determine the effect of increased temperature on dinoflagellate symbionts ${ }^{39}$ ) were not significantly different between control and heated corals until the final day when the corals where exposed to the organisms bleaching threshold ${ }^{40}$ (Figure 1c). This decrease in yield is characteristic of thermal damage to PSII and is a sign of "algal stress bleaching" 39 . This classic bleaching response is a symptom of chronic photoinhibition and eventual expulsion of Symbiodinium. Using this data we were able to define the bleaching threshold in the experiment as $34^{\circ} \mathrm{C}$ on day 8 , changes in gene expression that are seen before day 8 are therefore considered

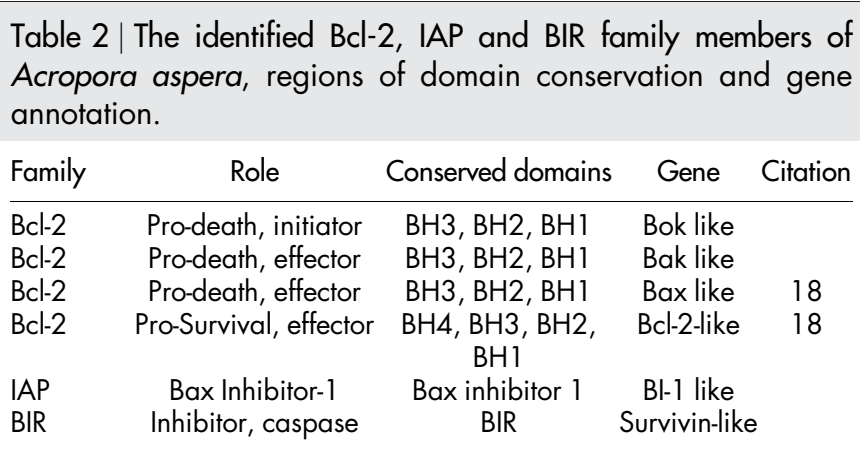



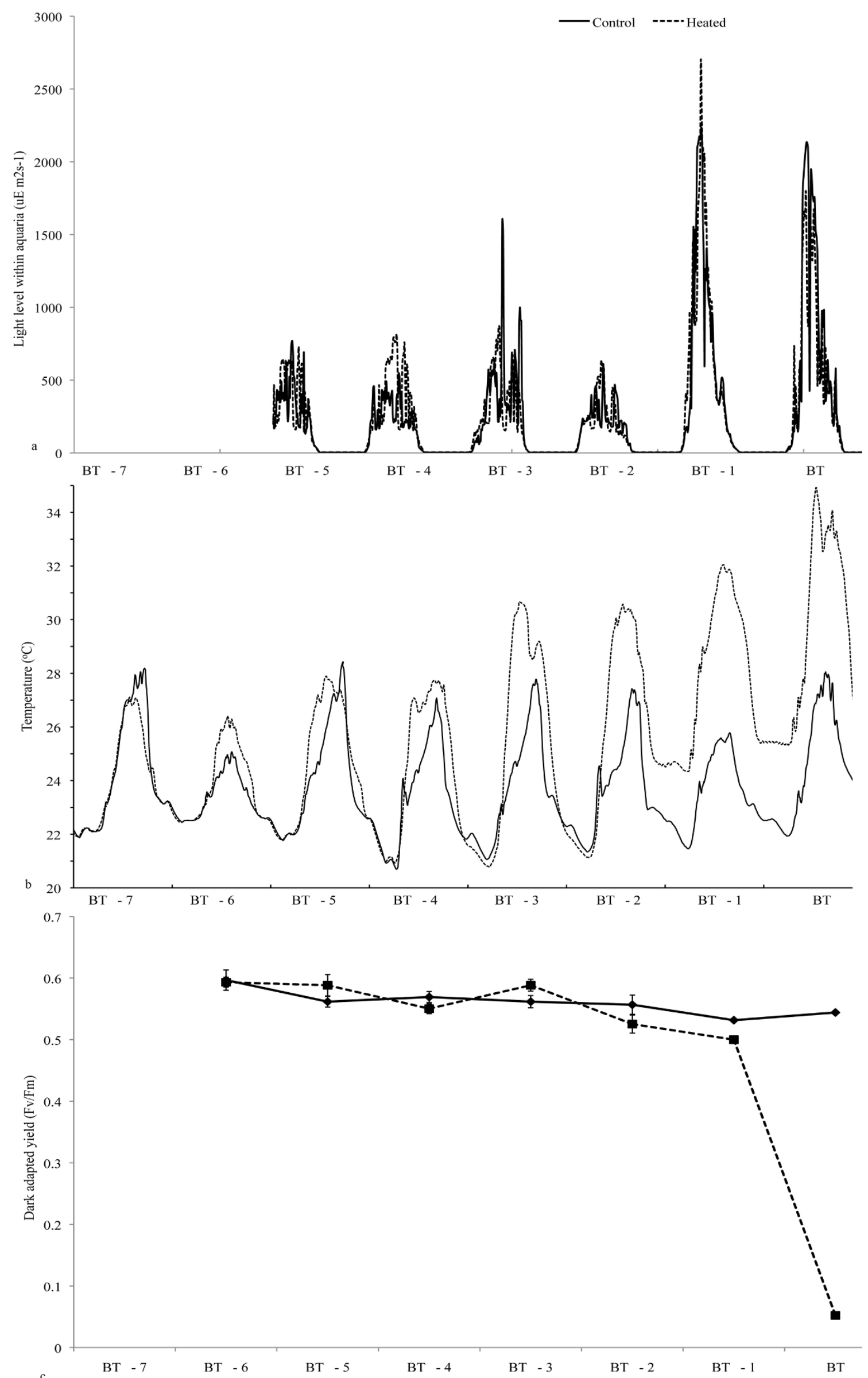


\begin{tabular}{|c|c|c|c|c|c|c|c|c|c|c|c|}
\hline & BT & $-3^{\circ} \mathrm{C}$ & & BT & $-2^{\circ} \mathrm{C}$ & BT & $-1{ }^{\circ} \mathrm{C}$ & & & BT & \\
\hline Gene & $8 \mathrm{am}$ & $1 \mathrm{pm}$ & $6 \mathrm{pm}$ & $8 \mathrm{am}$ & $1 \mathrm{pm}$ & $8 a m$ & $1 \mathrm{pm}$ & $6 \mathrm{pm}$ & $8 \mathrm{am}$ & $1 \mathrm{pm}$ & $6 \mathrm{pm}$ \\
\hline Bok & & $\begin{array}{c}0.4 \downarrow \\
p=0.001\end{array}$ & & & & & & & $\begin{array}{c}1.2 \uparrow \\
p=0.049\end{array}$ & $\begin{array}{c}0.4 \downarrow \\
p=0.002\end{array}$ & \\
\hline Bak & & $\begin{array}{c}1.6 \uparrow \\
p=0.018\end{array}$ & & & $\begin{array}{c}1.4 \uparrow \\
p=0.0012\end{array}$ & & & $\begin{array}{c}1.5 \uparrow \\
p=0.018\end{array}$ & $\begin{array}{c}1.8 \uparrow \\
p=0.001\end{array}$ & $\begin{array}{c}2.6 \uparrow \\
p=0.001\end{array}$ & $\begin{array}{c}2.4 \uparrow \\
p=0.002\end{array}$ \\
\hline Bax & & & $\begin{array}{c}1.2 \uparrow \\
p=0.001\end{array}$ & & & & $\begin{array}{c}2.0 \uparrow \\
p=0.009\end{array}$ & & $\begin{array}{c}1.5 \uparrow \\
p=0.002\end{array}$ & $\begin{array}{c}1.9 \uparrow \\
p=0.015\end{array}$ & $\begin{array}{c}3.8 \uparrow \\
p=0.003\end{array}$ \\
\hline $\mathrm{Bcl} 2$ & & $\begin{array}{c}7.1 \uparrow \\
p=0.002\end{array}$ & & & & & $\begin{array}{c}4.5 \uparrow \\
p=0.031\end{array}$ & $\begin{array}{c}8.6 \uparrow \\
p=0.001\end{array}$ & $\begin{array}{c}2.0 \uparrow \\
p=0.003\end{array}$ & $\begin{array}{c}28.5 \uparrow \\
p=0.002\end{array}$ & $\begin{array}{c}13.6 \uparrow \\
p=0.049\end{array}$ \\
\hline $\begin{array}{l}\text { BI-1 } \\
\text { BIR }\end{array}$ & & & $\begin{array}{c}1.6 \uparrow \\
p=0.001 \\
1.3 \uparrow \\
p=0.004\end{array}$ & & $\begin{array}{c}1.5 \uparrow \\
p=0.003\end{array}$ & $\begin{array}{c}1.8 \uparrow \\
p=0.005\end{array}$ & $\begin{array}{c}1.5 \uparrow \\
p=0.03 \\
1.6 \uparrow \\
p=0.017\end{array}$ & $\begin{array}{c}2.7 \uparrow \\
p=0.001\end{array}$ & $\begin{array}{c}1.4 \uparrow \\
p=0.049\end{array}$ & $\begin{array}{c}2.5 \uparrow \\
p=0.049 \\
0.5 \downarrow \\
p=0.001\end{array}$ & $\begin{array}{c}5.5 \uparrow \\
p=0.049 \\
0.4 \downarrow \\
p=0.001\end{array}$ \\
\hline
\end{tabular}

to be occurring before the onset of 'algal stress bleaching' and the resultant breakdown of the symbiosis.

Gene expression patterns during early heat stresses prior to the onset of coral bleaching. The expression of all six genes involved in apoptosis regulation was found to significantly change in A. aspera in the lead up to a thermal bleaching temperature when compared to control corals, but differed in both direction and scale (Table 3, Figure 2, 3). Expression of the Acropora Bok-like protein (Table 3, Figure 2a), was found to be significantly down regulated in response to thermal stress at $1 \mathrm{pm}$ at temperatures $3^{\circ} \mathrm{C}$ below the bleaching threshold. Also at this temperature, expression of the pro-apoptotic Bcl-2 family members Bak and Bax are found to be significantly upregulated. Significant up-regulation of Bak occurs at midday (cumulative light/temperature stress) whereas Bax gene expression is significantly up-regulated at $6 \mathrm{pm}$ at $3^{\circ} \mathrm{C}$ below the bleaching threshold (Figure 2c). Significant changes in gene expression of both Bak and $\mathrm{Bax}$ are also evident at $2^{\circ} \mathrm{C}$ and $1^{\circ} \mathrm{C}$ below the bleaching threshold (Table 3).

In addition there is also up-regulation of the anti-apoptotic Bcl-2, BI-1 and BIR prior to exposure to bleaching thresholds. Bcl-2 was upregulated 7.1 fold $(p=0.002)$ at $3^{\circ} \mathrm{C}$ below the bleaching threshold at $1 \mathrm{pm}$ (Table 3, Figure 3a), followed by a consistent up-regulation at $2^{\circ} \mathrm{C}$ and $1^{\circ} \mathrm{C}$ below the bleaching threshold. Both the anti-apoptotic Bax inhibitor-1 and BIR (Figure 3b,c) demonstrate clear patterns of up-regulation at $3^{\circ} \mathrm{C}$ below the bleaching threshold and reflects the increasing cumulative thermal stress. We find there is a 1.6 fold up-regulation $(p=0.001)$ in expression of BI-1 and 1.3 fold upregulation of $\operatorname{BIR}(p=0.004)$ evident at $6 \mathrm{pm}$ at $3^{\circ} \mathrm{C}$ below the bleaching threshold. BI-1 expression returns to control levels at 8 am on the following day but is then significantly elevated for the remainder of the pre-bleaching period. During the pre-bleaching period BIR is however subsequently only found to be up-regulated at $1 \mathrm{pm} 1^{\circ} \mathrm{C}$ below the bleaching threshold.

Gene expression patterns during exposure to the coral bleaching threshold. At bleaching temperatures (the final day of temperature stress, Table 3, Figure 1a) all pro-apoptotic and anti-apoptotic genes were differentially expressed when compared to controls. The proapoptotic Bok was up-regulated at 8 am but down-regulated at $1 \mathrm{pm}$ representing a large variation in expression during the day (Table 3 , Figure 2a). The significant down regulation of midday Bok-like gene expression occurs at both bleaching temperatures and $3^{\circ} \mathrm{C}$ below the bleaching threshold coinciding with the highest light-temperature stress (Table 3, Figure 1b,c). In contrast, both Bak and Bax gene expression remain significantly up-regulated by between 1.7 and 3.8 fold over the course of the day during the onset of coral bleaching (Table 3).

Both the anti-apoptotic Bcl-2 and BI-1 were up-regulated throughout the onset of bleaching with the highest levels found throughout the experimental period. Bcl-2 expression rose from a significant 2.0 fold up-regulation at 8 am to 28.5 fold, at $1 \mathrm{pm}$, and a 13.6 fold up-regulation at $6 \mathrm{pm}$ (Table3, Figure 3a). Similarly BI-1 rose from 1.4 fold up-regulation at 8 am to 2.5 , and 5.5 fold upregulation during the day (Figure $3 \mathrm{~b}$ ). In contrast, the apoptosis inhibitor BIR (survivin) is found to be significantly ( 0.2 fold) down-regulated at both $1 \mathrm{pm}$ and $6 \mathrm{pm}$ during the onset of bleaching following exposure to the bleaching threshold (Table 3, Figure 3c).

\section{Discussion}

The apoptotic network regulates cellular responses to stress and death signals and maintains the balance between life and death ${ }^{11-15}$. Both biotic (for example starvation and pathogens) and abiotic stimuli (for example exposure to ultraviolet light and heat stress) initiate this network ${ }^{12,13,16}$ and during thermal stress events on coral reefs, the coral animal is exposed to all of these stress signals over long time periods prior to the onset of the observable bleaching stress response. However how the coral organism regulates the cellular response to these signals and controls cell death prior to, and during, the bleaching response is largely unknown and we are yet to understand the broader significance of early stress impacts to the coral organism or the reef community.

Tchenov et al. ${ }^{41}$ recently proposed a model of coral cell death during bleaching, in which they suggest that some populations of cells within the host are irreversibly damaged by dinoflagellate generated ROS, while other cells suppress the cell death cascade, survive the stress event, and are the basis for tissue regeneration. Under the Tchenov model, an up-regulation of genes encoding both pro- and anti-apoptotic proteins would be expected during bleaching, and this was found in the current study. However we also find these changes occurring at temperatures lower than the bleaching threshold and prior to the onset of the bleaching response. Here we present substantial evidence to support the Tchenov model of cellular control of death and recovery from coral bleaching events and further suggest that early abiotic stressors, occurring prior to the onset of the

Figure 1 1 Light (a) and temperature (b) regimes within the aquaria of the experimental setup on outdoor decking at Heron Island Research station from $7^{\circ} \mathrm{C}$ below the study organisms physiological bleaching threshold, BT, up to exposure to the bleaching threshold, BT, adjacent to the reef flat and the dark apdapted photosynthetic yield of endosymbiotic dinoflagellates in both control and thermal stress conditions (c) throughout the experimental period. 


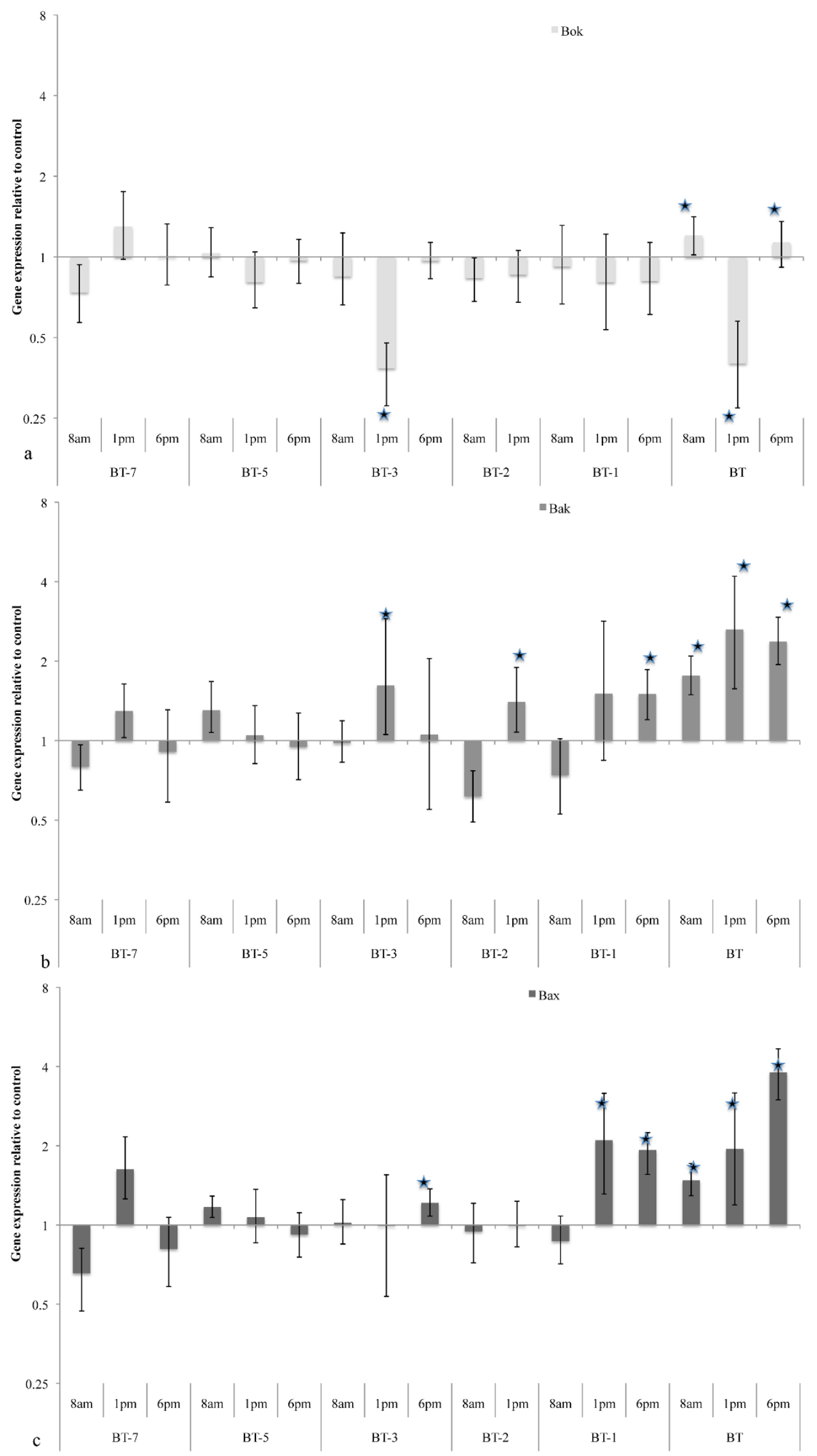

Figure 2| Gene expression (represented as fold change) of the identified pro-apoptotic Bcl-2 family members Bok (a), Bak (b) and Bax (c) relative to control, in the coral Acropora aspera in response to daily $(8 \mathrm{am}, 1 \mathrm{pm}, 6 \mathrm{pm})$ environmental temperature fluctuations within the experimental system from $7^{\circ} \mathrm{C}$ below the study organisms physiological bleaching threshold, BT, up to exposure to the bleaching threshold, BT. 


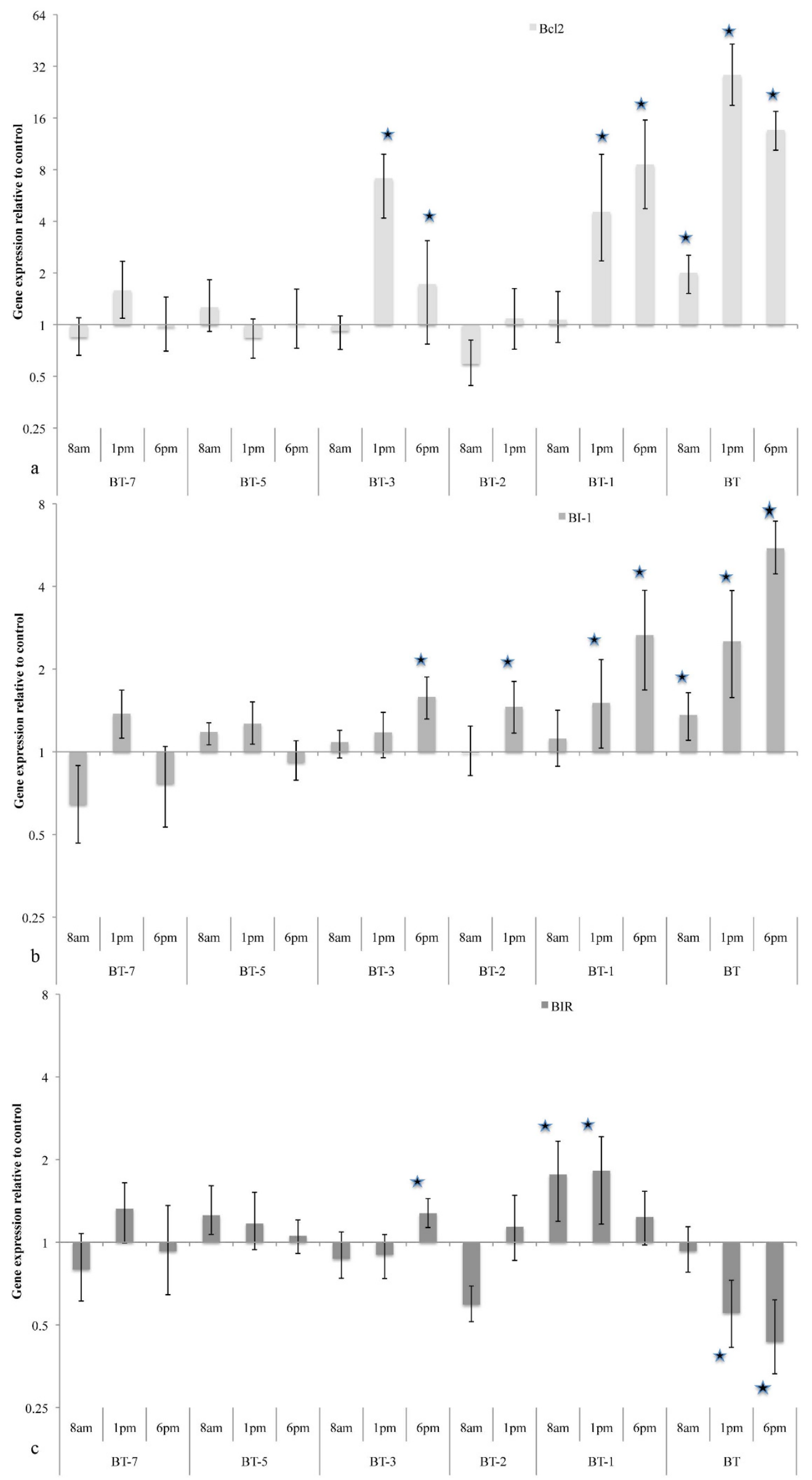


bleaching phenomena also strongly influence the impact of thermal stress events to the coral. In fact the complexity of apoptotic gene expression in thermal stress responses mirrors that of higher organisms and is indicative of the myriad of stress signals being concurrently interpreted.

Upstream apoptotic regulators in the Bcl-2 family have been shown in higher organisms to function as a cellular life/death switch and to be key sentinels of cell death ${ }^{19}$ which are up-regulated in response to cell death signals ${ }^{17}$. This is the first study of lower organisms to characterize the presence of a Bcl-2 family member with $\mathrm{BH}$ and nuclear transporter domains consistent with the upstream apoptosis regulator, Bok. In mammalian cells, where the function of Bok has been determined, an upregulation in expression is independent of anti-apoptotic Bcl-2 family members and responds to nuclear damage $^{17}$. In the present study we find a significant up-regulation of coral Bok-like expression coinciding with the peak thermal impacts to the coral host, potentially reflecting thermal damage to the nucleus occurring prior to the onset of coral bleaching. However this is the first study to demonstrate a significant down regulation in Bok gene expression, which was observed coinciding with peak light/ temperature interactions $3^{\circ} \mathrm{C}$ prior to and during the bleaching threshold. Further investigation of this protein is warranted to determine if it is also a sentinel of nuclear damage and to determine the biological significance of a down regulation of this protein.

Unlike upstream regulators, other Bcl-2 family members however interact with each other to control damage to the cell's organelles. Pro-apoptotic Bax and Bak, interact with anti-apoptotic Bcl-2 (and $\mathrm{Bcl}-\mathrm{x})$ to form heterodimeric proteins and an excess of Bax or Bak within the cytoplasm results in the pro-apoptotic targeting and permeabilisation of both the mitochondria and the endoplasmic reticulum membranes ${ }^{20,21}$. In the present study the largest fold gene expression changes were observed for the anti-apoptotic Bcl-2. Bcl-2 is widely linked to anti-oxidant function in cells and cells expressing Bcl-2 are considered to be resistant to oxidant stress. A 7.1 fold up-regulation in Bcl-2 expression was first observed from $3^{\circ} \mathrm{C}$ below the bleaching threshold and expression remained significantly up-regulated (through to a 28.5 fold up-regulation) until bleaching occurred. This large up-regulation indicates a strong anti-apoptotic and anti-oxidant response from the host prior to the onset of coral bleaching. Importantly, we also find the peak Bcl-2 expression clearly evident during the highest daily cumulative light/temperature stress, lower at the $6 \mathrm{pm}$ temperature stress events (low light but the longest daily thermal stress exposure) and lowest at the $8 \mathrm{am}$ time point following the overnight recovery period. An interaction between light and temperature stress is a necessary determinant of coral bleaching, in that without the cumulative impact of light and temperature on the dinoflagellate photosystems the coral has a higher thermal threshold before mortality occurs ${ }^{39}$. However apoptotic cell death is clearly evident within gastrodermal cells (those holding the endosymbiotic dinoflagellate) $3^{\circ} \mathrm{C}$ prior to the onset of bleaching ${ }^{7}$. Given that the sustained upregulation of Bcl-2 prior to bleaching is also accompanied by significant up-regulation of both pro-apoptotic Bax and Bak, the anti-oxidant and anti-apoptotic function of Bcl-2 is likely to vary across the organism, have cell and tissue specific regulation and these factors maybe important in determining the capacity of the organism as a whole to control cell death, mortality and ultimately cellular regeneration.

The fine control of cell death in multi-cellular organisms is further regulated through downstream inhibitors. Bax inhibitor-1 (BI-1) is highly conserved and its inhibitory (anti-apoptotic) role has been demonstrated in both plant and animal species ${ }^{42,43}$. The protein is located within the endoplasmic reticulum membrane where it prevents targeting of the pro-apoptotic $\mathrm{Bcl}-2$ family proteins, confers protection from ER stress, and prevents the generation of ROS within the cell ${ }^{44}$. In the present study we find a significant and sustained up regulation of BI-1 occurring throughout the early thermal stress responses and during bleaching onset. While ROS generation due to ER stress has been proposed as one of the underlying mechanisms in coral bleaching ${ }^{4,45}$ the prevention of ER damage in some cells maybe a key mechanism underlying the capacity for coral recovery and regeneration. Over expression of BI-1 is linked to increased cell adhesion through a direct interaction of the protein with $\operatorname{actin}^{46}$. Therefore further investigation of the role of BI-1 is warranted to determine if this is a mechanism for maintaining cell and tissue integrity of cells not damaged during coral stress and bleaching. However unlike the anti-apoptotic Bcl-2 and BI-1, the apoptosis inhibitor BIR (survivin) is significantly down regulated only during the onset of coral bleaching. Survivin functions by suppressing both intrinsic and extrinsic apoptotic pathways and blocking caspase-9 function (for review se ${ }^{22}$ ). Previous studies in higher organisms have linked low expression of BIR with an increased sensitivity to pro-apoptotic stress signals and to cell death execution ${ }^{47,48}$, an upregulation however is considered critical for prevention of the cell death cycle $^{47}$. In the current study there is an up-regulation in the expression of this gene prior to exposure to the bleaching threshold, but a clear down-regulation at the highest temperature exposure and the onset of coral bleaching. If survivin function is analogous to that of higher organisms, a down regulation during bleaching onset provides evidence that stress-affected cells have in fact entered an irreversible terminal state and there is a tipping of the cellular balance from survival to death.

Here we show that the molecular machinery governing cell death in the tightly coupled coral-dinoflagellate symbiosis is highly complex and responds significantly to subtle, daily changes in the environment, and at temperatures that are generally considered to have little impact on holobiont function. The kinetics of apoptotic gene expression during thermal stress responses highlights the need to better understand cellular processes occurring prior to and during bleaching events, and the need to determine the mechanisms which underlie coral mortality and recovery in response to environmental stress. Based on the current understanding of coral apoptosis we provide a basic conceptual model of cell death function within the coral symbiotic system during thermal stress (Figure 4) and demonstrate that prior to bleaching there is an initiation of the cell death cascade and a potential tipping of the cellular balance from survival to death.

However one major constraint in understanding this complex cell death system is a lack of information on the cell biology, cellular differentiation, tissue function and the cellular recovery processes in coral. It is likely that the regulation of apoptosis found in the current study represents a homogenization of responses across distinct cell and tissue types within a complex, colonial, habitat under which there is significant biotic and abiotic variation ${ }^{49}$. All of these factors likely have significant impacts on the capacity of the coral to regenerate tissues and recover from bleaching events.

\section{Methods}

Experimental design and sample collection.. Branches from coral colonies of Acropora aspera (cream morph) of at least $7 \mathrm{~cm}$ in length $(\mathrm{n}, 148)$ were collected from three adjacent coral patch colonies on the Heron Island reef flat. A. aspera (tan morph) was selected as the study organism due to its previously documented high bleaching threshold $\left(34^{\circ} \mathrm{C}\right)$ compared to other reef flat corals and species morphs in the local area ${ }^{50}$, this species has also been widely used in similar studies of Acroporid physiology due to this comparatively high thermal threshold ${ }^{(7,50-53)}$. The collected coral branches were relocated to the adjacent research station, placed upright in stands and held in flow through aquaria within 30 mins of collection from the reef

Figure 3 Gene expression (represented as fold change) of the identified anti-apoptotic of Bcl-2 (a) Bax inhibitor BI-1 (b) and BIR/survivin (c) relative to control in the coral Acropora aspera in response to daily $(8 \mathrm{am}, 1 \mathrm{pm}, 6 \mathrm{pm})$ environmental temperature fluctuations within the experimental system from $7^{\circ} \mathrm{C}$ below the study organisms physiological bleaching threshold, BT, up to exposure to the bleaching threshold, BT. 


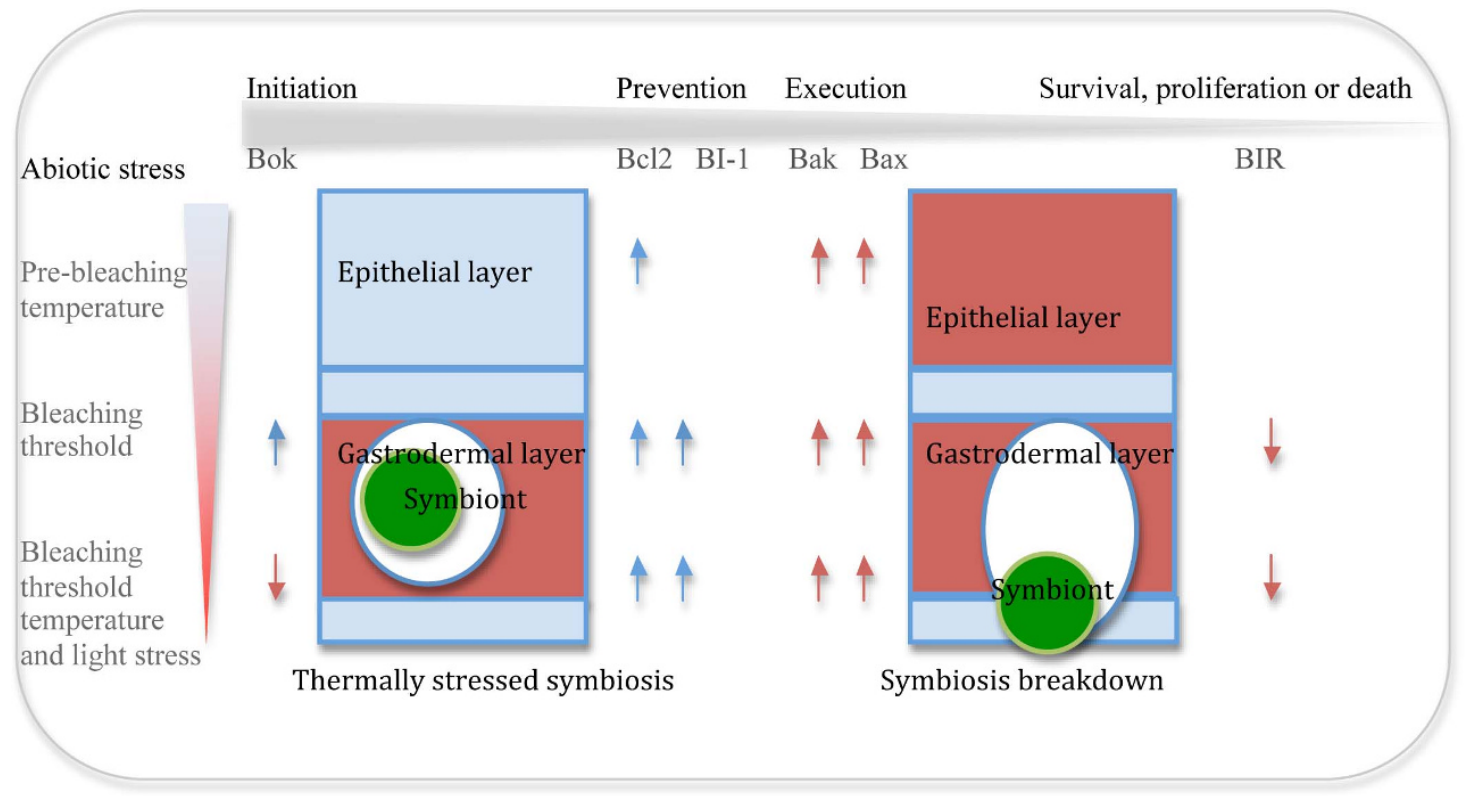

Figure $4 \mid$ A conceptual model of the cell death and symbiosis breakdown under temperature and light stress in coral. Red coloration indicates morphological evidence for apoptotic cell death; blue block coloration indicates no evidence for apoptotic cell death. Red arrow, significant change in gene expression related to cell death. Blue arrow, significant gene expression change related to cell survival. Grey arrow, indicates progression of the apoptosis cascade.

flat. Handling stress was minimized through the 30 mins collection period and coral branches were transported in low density to prevent branches touching and sloughing mucus, with high volume seawater $(40 \mathrm{~L})$ collected from the location of coral collection. Coral branches were randomly assigned to 6 of $60 \mathrm{~L}$ experimental aquaria and were held in flow through ambient seawater for 4 days to acclimate and recover from collection. Recovery was evident from tissue re-growth over the collection break at the base of each branch. Following the recovery period three replicate aquaria were designated experimental tanks and three replicate aquaria designated control ambient tanks designated control ambient tanks. Each aquaria was supplied each aquaria where supplied with seawater obtained from the adjacent reef flat through a sand filter system, into $1000 \mathrm{~L}$ sump tanks in which internal recirculation heaters were used to adjust the seawater to the daily temperature regimes. High volume sump tanks were used to supply seawater to tanks to allow for variation in daily water temperatures to reflect those experienced within the adjacent reef flat conditions and to prevent variability in thermal regimes between the replicate aquaria. To replicate the conditions found on Heron Island reef flat during periods of thermal stress, experimental tanks were exposed to increasing daily thermal stress of $1^{\circ} \mathrm{C}$ above the previous day's thermal maximum up to the study organism bleaching threshold $\left(34^{\circ} \mathrm{C}\right)$ (Figure 1). Thermal stress was maintained throughout the daylight period prior to the temperature being returned to ambient conditions overnight as a recovery period. Aquaria water temperatures were increased daily at 8 am and seawater temperatures gradually increased reaching the daily maximal temperature coinciding with the highest light period at midday (Figure 1). Control tanks were maintained at ambient sea surface temperatures throughout the diurnal period with temperatures fluctuating between the daily thermal maximum and night time thermal minimum of $21-27^{\circ} \mathrm{C}$. Coral branches $(\mathrm{n}, 2)$ were randomly sampled from each aquaria daily at 8 am following the overnight ambient temperature recovery period, at $1 \mathrm{pm}$ following exposure to the maximum temperature and high light period of the day, and at $6 \mathrm{pm}$ following cumulative exposure to 10 hours daily thermal stress (total of $n, 36$ coral branches collected per day for 9 consecutive days). Replicate coral branches ( $\mathrm{n}, 6$ per tank) were also analysed daily to determine photosynthetic efficiency of endosymbiotic dinoflagellates ${ }^{54,55}$ using an imaging Pulsed Amplitude Modulated (iPAM) fluorometer (imaging-PAM, Waltz Gmbh, Germany). At 6 pm each day coral branches were dark adapted for $30 \mathrm{~min}$ and the dark adapted quantum yield of photosystem II determined using the Genty equation $\mathrm{Y}=(\mathrm{Fm}-\mathrm{Fo}) / \mathrm{Fm}^{56}$.

Sequence identification. Two key members of the Bcl-2 family of apoptotic regulators, $\mathrm{Bcl}-2$ and $\mathrm{Bax}$, have previously been identified from Acropora millepora $^{33}$ and $A$. aspera ${ }^{7}$. The full length cDNA sequence of two further, previously unidentified, members of the Bcl-2 family (Bak-like and Bok-like) and two key downstream inhibitors of apoptosis, BIR (survivin) and BI (Bax inhibitor-1), were identified from the A. millepora EST and 454 databases $^{57}$. Newly identified regulators and inhibitors of apoptosis were aligned and compared to previously identified apoptosis proteins using the NCBI blast server.

Sample processing and quantitative PCR. Upon collection from the aquaria coral branches were immediately snap frozen in liquid nitrogen and stored at $-80^{\circ} \mathrm{C}$ prior to sample processing. Coral branches were then crushed and homogenized under liquid nitrogen prior to RNA extraction and stored at $-80^{\circ} \mathrm{C}$. mRNA was isolated from approximately $100 \mathrm{mg}$ of homogenized coral branch using the commercial available Dynabeads Olgio dT kit (Invitrogen, product \#610-05) following the manufacturers instructions (as per ${ }^{58}$ ). Approximately $400 \mathrm{ng}$ mRNA was extracted from each sampled and the integrity of each extraction confirmed using the ND-1000 spectrophotometer $(260 \mathrm{~nm}$ ) (Nanodrop Technologies). cDNA was constructed using Superscript III First Strand Synthesis Supermix for RT-PCR (Invitrogen Cat \# 18080-400) following the manufacturer's instructions and the resultant CDNA was stored at $-20^{\circ} \mathrm{C}$ prior to quantitative PCR (qPCR). Primers for qPCR were design in PrimerSelect Lasergene 8 (Table 1), PCR confirmed the calculated amplicon sizes (70-90 bp) and sequencing of the generated PCR product confirmed the sequence homology to higher organism cell death genes within A. aspera. The melting temperature curves for each gene amplicon were determined and the efficiency of gene target amplification was established using 4 serial dilutions of cDNA template. Previously determined coral house keeping genes (HKG) appropriate for thermal stress experiments, L9, S7 and Ado ${ }^{58}$, were selected and tested for stability within the current experimental scenario. Each sample was analysed in triplicate to control for technical variability and GOI expression relative to HKG at each time point was determined using the REST analysis ${ }^{59}$.

1. Mumby, P. J. \& Steneck, R. S. in Coral Reefs: An Ecosystem in Transition eds Zvy Dubinsky \& Noga Stambler) 509-519 (Springer Netherlands, 2011).

2. Hoegh-Guldberg, O. Climate change, coral bleaching and the future of the world's coral reefs. Marine and Freshwater Research 50, 839-866 (1999).

3. Brown, B. E. Coral bleaching: causes and consequences. Coral Reefs 16, s129-s138 (1997).

4. Weis, V. M. Cellular mechanisms of Cnidarian bleaching: stress causes the collapse of symbiosis. Journal of Experimental Biology 211, 3059-3066 (2008).

5. Baird, A. H., Bhagooli, R., Ralph, P. J. \& Takahashi, S. Coral bleaching: the role of the host. Trends in Ecology \& Evolution 24, 16-20 (2009).

6. Leggat, W., Whitney, S. M. \& Yellowlees, D. Is coral bleaching due to the instability of the zooxanthellae dark reactions? Symbiosis 37, 137-153 (2004).

7. Ainsworth, T. D., Hoegh-Guldberg, O., Heron, S. F., Skirving, W. J. \& Leggat, W. Early cellular changes are indicators of pre-bleaching thermal stress in the coral host. Journal of Experimental Marine Biology and Ecology 364, 63-71 (2008).

8. Gates, R. D., Baghdasarian, G. \& Muscatine, L. Temperature stress causes host cell detachment in symbiotic cnidarians: Implications for coral bleaching. The Biological Bulletin 182, 324-332 (1992).

9. Dunn, S. R., Bythell, J. C., Le Tissier, M. D. A., Burnett, W. J. \& Thomason, J. C. Programmed cell death and cell necrosis activity during hyperthermic stressinduced bleaching of the symbiotic sea anemone Aiptasia sp. Journal of Experimental Marine Biology and Ecology 272, 29-53 (2002).

10. Levy, O. et al. Complex diel cycles of gene expression in coral-algal symbiosis. Science 331, 175 (2011).

11. Elmore, S. Apoptosis: A review of programmed cell death. Toxicologic Pathology 35, 495-516 (2007) 
12. Gross, A., McDonnell, J. M. \& Korsmeyer, S. J. BCL-2 family members and the mitochondria in apoptosis. Genes \& Development 13, 1899-1911 (1999).

13. Kultz, D. molecular and evolutionary basis of the cellular stress response. Annual Review of Physiology 67, 225-257 (2005).

14. Leber, B., Lin, J. \& Andrews, D. Embedded together: The life and death consequences of interaction of the Bcl-2 family with membranes. Apoptosis 12 897-911 (2007).

15. Zmasek, C. M., Zhang, Q., Ye, Y. \& Godzik, A. Surprising complexity of the ancestral apoptosis network. Genome Biology 8, R226 (2007).

16. He, R. et al. Metacaspase- 8 Modulates Programmed Cell Death Induced by Ultraviolet Light and $\mathrm{H}_{2} \mathrm{O}_{2}$ in Arabidopsis. Journal of Biological Chemistry 283, 774-783 (2008).

17. Yakovlev, A. G. et al. BOK and NOXA Are Essential Mediators of p53-dependent Apoptosis. Journal of Biological Chemistry 279, 28367-28374 (2004).

18. Cory, S. \& Adams, J. M. The Bcl-2 family: regulators of the cellular life-or-death switch. Nat Rev Cancer 2, 647-656 (2002).

19. Willis, S. N. et al. Apoptosis Initiated When BH3 Ligands Engage Multiple Bcl-2 Homologs, Not Bax or Bak. Science 315, 856-859 (2007).

20. Hockenbery, D. M., Oltvai, Z. N., Yin, X.-M., Milliman, C. L. \& Korsmeyer, S. J. $\mathrm{Bcl}-2$ functions in an antioxidant pathway to prevent apoptosis. Cell 75, 241-251 (1993).

21. Susnow, N., Zeng, L., Margineantu, D. \& Hockenbery, D. M. Bcl-2 family proteins as regulators of oxidative stress. Seminars in Cancer Biology 19, 42-49 (2009).

22. Altieri, D. C. Molecular circuits of apoptosis regulation and cell division control: The survivin paradigm. Journal of Cellular Biochemistry 92, 656-663 (2004).

23. Guha, M. \& Altieri, D. C. Survivin as a global target of intrinsic tumor suppression networks. Cell Cycle 8, 2708-2710 (2009).

24. Kerr, J. F., Wyllie, A. H. \& Currie, A. R. Apoptosis: A Basic Biological Phenomenon with Wideranging Implications in Tissue Kinetics. Br J Cancer 26, 239-257 (1972).

25. Jacobson, M. D., Weil, M. \& Raff, M. C. Programmed Cell Death in Animal Development. Cell 88, 347-354 (1997).

26. Dunn, S. R., Phillips, W. S., Spatafora, J. W., Green, D. R. \& Weis, V. M. Highly conserved caspase and Bcl-2 homologues from the sea anemone Aiptasia pallida: lower metazoans as models for the study of apoptosis evolution. J Mol Evol 63 , 95-107 (2006)

27. Lasi, M., David, C. \& Böttger, A. Apoptosis in pre-Bilaterians: Hydra as a model. Apoptosis 15, 269-278 (2010).

28. Galliot, B. \& Chera, S. The Hydra model: disclosing an apoptosis-driven generator of Wnt-based regeneration. Trends in cell biology 20, 514-523 (2010).

29. David, C. N. et al. Hydra and the evolution of apoptosis. Integrative and Comparative Biology 45, 631-638 (2005).

30. Mumby, P. J. et al. Unprecedented bleaching-induced mortality in Porites spp. at Rogiroa Atoll, French Polynesia. Marine Biology 139, 183-189 (2001).

31. Shinzato, C. et al. Using the Acropora digitifera genome to understand coral responses to environmental change. Nature advance online publication, doi:http://www.nature.com/nature/journal/vaop/ncurrent/abs/ nature10249.html\#supplementary-information (2011)

32. Grasso, L. C. et al. The biology of coral metamorphosis: Molecular responses of larvae to inducers of settlement and metamorphosis. Developmental Biology 353, 411-419 (2011).

33. Pernice, M. et al. Regulation of Apoptotic Mediators Reveals Dynamic Responses to Thermal Stress in the Reef Building Coral Acropora millepora. PLoS ONE 6, e16095 (2011)

34. Dunn, S. R., Thomason, J. C., Le Tissier, M. D. A. \& Bythell, J. C. Heat stress induces different forms of cell death in sea anemones and their endosymbiotic algae depending on temperature and duration. Cell Death Differ 11, 1213-1222 (2004).

35. Dunn, S. R. \& Weis, V. M. Apoptosis as a post-phagocytic winnowing mechanism in a coral-dinoflagellate mutualism. Environmental Microbiology 11, 268-276 (2009).

36. Danial, N. N. \& Korsmeyer, S. J. Cell Death: Critical Control Points. Cell 116, 205219 (2004).

37. Ainsworth, T. D., Thurber, R. V. \& Gates, R. D. The future of coral reefs: a microbial perspective. Trends in Ecology \& Evolution In Press, Corrected Proof

38. Putnam, N. H. et al. Sea Anemone Genome Reveals Ancestral Eumetazoan Gene Repertoire and Genomic Organization. Science 317, 86-94 (2007).

39. Fitt, W. K., Brown, B. E., Warner, M. E. \& Dunne, R. P. Coral bleaching interpretation of thermal tolerance limits and thermal threshold in tropical corals. Coral Reefs 20, 51-65 (2001).

40. Seibt, C. \& Schlichter, D. Compatible intracellular ion composition of the host improves carbon assimilation by zooxanthellae in mutualistic symbioses. Naturwissennschaften 88, 382-386 (2001).
41. Tchernov, D. et al. Apoptosis and the selective survival of host animals following thermal bleaching in zooxanthellate corals. Proceedings of the National Academy of Sciences (2011)

42. Chae, H.-J. et al. Evolutionarily conserved cytoprotection provided by Bax Inhibitor-1 homologs from animals, plants, and yeast. Gene 323, 101-113 (2003).

43. Watanabe, N. \& Lam, E. Arabidopsis Bax inhibitor-1 functions as an attenuator of biotic and abiotic types of cell death. The Plant Journal 45, 884-894 (2006).

44. Xu, C., Bailly-Maitre, B. \& Reed, J. C. Endoplasmic reticulum stress: cell life and death decisions. The Journal of Clinical Investigation 115, 2656-2664 (2005).

45. Desalvo, M. K. et al. Differential gene expression during thermal stress and bleaching in the Caribbean coral Montastraea faveolata Molecular Ecology 17, 3952-3971 (2008).

46. Lee, G.-H. et al. Bax Inhibitor 1 Increases Cell Adhesion through Actin Polymerization: Involvement of Calcium and Actin Binding. Mol. Cell. Biol. 30, 1800-1813 (2010).

47. Guo, M. \& Hay, B. A. Cell proliferation and apoptosis. Current Opinion in Cell Biology 11, 745-752 (1999).

48. Kobayashi, K., Hatano, M., Otaki, M., Ogasawara, T. \& Tokuhisa, T. Expression of a murine homologue of the inhibitor of apoptosis protein is related to cell proliferation. Proceedings of the National Academy of Sciences of the United States of America 96, 1457-1462 (1999).

49. Ainsworth, T. D., Thurber, R. V. \& Gates, R. D. The future of coral reefs: a microbial perspective. Trends in Ecology \& Evolution 25, 233-240 (2010).

50. Dove, S. Scleractinian corals with photoprotective host pigments are hypersensitive to thermal bleaching. Marine Ecology Progress Series 272, 99-116 (2004).

51. Leggat, W., Hoegh-Guldberg, O., Dove, S. \& Yellowlees, D. Analysis of an EST library from the dinoflagellate (Symbiodinium sp.) symbiont of reef-building corals. Journal of Phycology 43, 1010-1021 (2007).

52. Brown, B. E. \& Dunne, R. P. Solar radiation modulates bleaching and damage protection in a shallow water coral. Marine Ecology Progress Series 362, 99-107 (2008).

53. Middlebrook, R., Hoegh-Guldberg, O. \& Leggat, W. The effect of thermal history on the susceptibility of reef-building corals to thermal stress. Journal of Experimental Biology 211, 1050-1056 (2008).

54. Jones, R. J., Kildea, T. \& Hoegh-Guldberg, O. PAM chlorophyll fluorometry: a new in situ technique for stress assessment in scleractinian corals, used to examine the effects of cyanide from cyanide fishing. Marine Pollution Bulletin 38, 864-874 (1999).

55. Jones, R. J. \& Hoegh-Guldberg, O. Diurnal changes in the photochemical efficiency of the symbiotic dinoflagellates (Dinophyceae) of corals: photoprotection, photoinactivation and the relationship to coral bleaching. Plant, Cell and Environment 24, 89-99 (2001).

56. Genty, B., Briantais, J. M. \& Baker, N. R. The relationship between the quantum yield of photosynthetic electron transport and quenching of chlorophyll fluorescence. Biochimica et Biophysica acta 990, 87-92 (1989).

57. Miller, D. J. et al. The innate immune repertoire in Cnidaria - ancestral complexity and stochastic gene loss. Genome Biol 8, R59 (2007).

58. Csar et al. Variation in antioxidant gene expression in the scleractinian coral Acropora millepora under laboratory thermal stress. Marine Ecology Progress Series 392, 93-102 (2009)

59. Pfaffl, M. W., Horgan, G. W. \& Dempfle, L. Relative expression software tool (REST) for group-wise comparison and statistical analysis of relative expression results in real-time PCR. Nucleic Acids Research 30, e36 (2002).

\section{Author contributions}

TA, BL conducted the field experiments and sample collection. BL, FS, KW, LU, TA conducted the sample processing, data collection and data analysis. TA, BL, DM, DY wrote the manuscript.

\section{Additional information}

Competing financial interests: The authors declare no competing financial interests.

License: This work is licensed under a Creative Commons

Attribution-NonCommercial-ShareAlike 3.0 Unported License. To view a copy of this license, visit http://creativecommons.org/licenses/by-nc-sa/3.0/

How to cite this article: A.T.D. et al. Defining the tipping point. A complex cellular life/ death balance in corals in response to stress. Sci. Rep. 1, 160; DOI:10.1038/srep00160 (2011) 